\title{
PRECISAMOS FALAR SOBRE TEMER: \\ O ESTRANHAMENTO \\ NA VOZ
}

\section{NECESITAMOS HABLAR SOBRE TEMER: EL EXTRAÑAMIENTO EN LA VOZ}

\author{
WE NEED TO TALK ABOUT TEMER: THE STRANGENESS IN THE VOICE
}

Luciana Iost Vinhas*

Universidade Federal de Pelotas

\begin{abstract}
RESUMO: O momento político do Brasil no ano de 2016 traz à tona a opacidade do discurso político, cuja materialização ocorre em diferentes formas de existência material. O presente trabalho se propõe a realizar uma análise da voz de Michel Temer, vicepresidente do Governo Dilma Rousseff, em seu primeiro pronunciamento enquanto Presidente Interino. O percurso analítico do trabalho começa a partir da identificação do estranhamento (ERNST, 2009) na materialidade vocal, entendida como uma materialidade discursiva diferenciada: a voz de Michel produz um efeito de falha no ritual. Analisamos, então, os efeitos de sentido produzidos a partir dessa voz rouca, solapada, engasgada, tentando relacioná-la ao interesse principal da Análise de Discurso de tradição francesa: a ligação entre inconsciente e ideologia.

PALAVRAS-CHAVE: Voz. Estranhamento. Análise de Discurso.
\end{abstract}

RESUMEN: El momento político brasileño del año 2016 presenta la opacidad del discurso político, cuya materialización se produce en diferentes formas de existencia material. Este estudio tiene como objetivo realizar un análisis de la voz de Michel Temer, vicepresidente del Gobierno Dilma Rousseff, en su primer discurso como Presidente Interino. El transcurso analítico del trabajo empieza por la identificación del extrañamiento (ERNST, 2009) en la materialidad vocal, entendida como una materialidad discursiva diferenciada: la voz de Michel produce un efecto de falla en el ritual. Analizamos, entonces, los efectos de sentido producidos por la voz ronca, ahogada, tratando de relacionarla al principal interés del Análisis de Discurso de tradición francesa: la conexión entre la ideología y el inconsciente.

PALABRAS CLAVE: Voz. Extrañamiento. Análisis de Discurso.

ABSTRACT: The Brazilian political moment in 2016 presents the opacity of the political discourse. The materialization of this discourse is produced in different forms of material existence. This study has as its objective to analyze Michel Temer's voice, who was the Vice-President in Dilma Roussefs Government. The analysis will focus on his first speech as Acting President. The analytical path of the study starts through the identification of the strangeness (ERNST, 2009) in the vocal materiality, which is understood as a discursive materiality with a different status: Michel's voice produces an effect of failure in the ritual. We analyze, then, the sense effects produced by this sapped, choked voice, trying to relate it to the main interest in the French Discourse Analysis: the connection between ideology and unconsciousness.

KEYWORDS: Voice. Strangeness. Discourse Analysis.

\footnotetext{
* Luciana Iost Vinhas é Professora de Língua Portuguesa na Universidade Federal de Pelotas (UfPel). É Doutora em Letras pela Universidade Federal do Rio Grandedo Sul (UFRGS). E-mail: lucianavinhas@gmail.com.
} 


\section{INTRODUÇÃO}

O atravessamento da Análise de Discurso na minha vida provocou uma transformação na forma como eu me representava como sujeito. Seria um movimento de desidentificação? Não saberia dizê-lo, tampouco é este o objetivo do presente texto. É importante, contudo, reconhecer que essa virada subjetiva não se deu por acaso: tal responsabilidade pousa no papel desempenhado por minha professora na graduação em Letras, orientadora de Mestrado e de Pós-Doutorado, Profa. Aracy Graça Ernst, cujas força teórica e militância discursiva contribuíram, de forma decisiva, para a minha formação profissional e pessoal. Foi com a Aracy que aprendi que, no âmbito das Letras, podemos pensar sobre a relação entre a linguagem e a ideologia; podemos pensar na linguagem pela perspectiva da transformação social, de forma a não reproduzirmos aquilo que nos oprime.

Desse modo, não poderia escrever um texto em homenagem à minha orientadora que não fosse um texto de questionamento. Parece-me necessário que se contribua com um debate sobre o contexto sócio-histórico-ideológico no qual o Brasil se encontrou em 2016, ano em que se desenrolou um severo embate acerca das condições de manutenção da democracia do país. Desde dezembro de 2015, convivemos com ânimos alterados em função da abertura do processo de impeachment contra a Presidenta Dilma Rousseff. Em 12 de maio de 2016, amanhecemos com a notícia de que o Senado Federal, em votação que durou toda a madrugada, aprovou o pedido de impeachment contra a Presidenta. Setenta e sete senadores julgaram que Dilma cometeu crime de responsabilidade, e, em função disso, seu afastamento da Presidência foi imediato. O placar do impeachment, muito próximo de um placar de um jogo de futebol, anunciava um acontecimento discursivo na base jurídica, política e ideológica brasileira: pela primeira vez na história do país, um Presidente era afastado do cargo através do processo de impeachment, sem renunciar nem pedir licença. Dentro e fora do Congresso, era possível escutar gritos de "Ganhamos!". Um "ganhamos" à direita. Entretanto, em todo esse cenário, algo não soa bem...

Tal fato nos conduz à memória do caso do ex-presidente Fernando Collor de Melo, o qual teve seu afastamento julgado no Congresso Nacional, mas preferiu a renúncia, tornando-se inelegível por oito anos. Além disso, outro diferencial com relação ao processo de impeachment de Dilma é que, antes da votação na Câmara, foi aberta uma Comissão Parlamentar de Inquérito em função de acusações de corrupção denunciadas pela imprensa. Depois de meses de investigação parlamentar, o impeachment foi aprovado na Câmara e no Senado, sendo seguido pela renúncia de Collor no dia 29 de dezembro de 1992.

O acontecimento histórico do dia 12 de maio de 2016 se transforma, então, em um acontecimento discursivo, segundo uma intuição teórica da autora deste texto, posto que promove um encontro entre uma memória e uma atualidade (PÊCHEUX, 2006), uma subversão na superestrutura jurídico-político-ideológica, uma reconfiguração no funcionamento das formações discursivas. Tal acontecimento é acompanhado, portanto, de mudança nas condições de produção do discurso, pois, conforme Pêcheux e Fuchs (1997, p. 11), toda formação discursiva diz respeito a condições de produção específicas. A voz que ecoa do grito de "Ganhamos" da direita vem acompanhada de outras vozes: vozes que solapam, que falham, que silenciam. E, também, vozes cínicas que parecem não falhar em conversas telefônicas ${ }^{1}$ que colocam em evidência a causa daquilo que falha, o fogo que deu origem à fumaça.

Essas vozes são o objeto do presente texto. Na verdade, trabalharei com a noção de estranhamento, conforme proposta em Ernst (2009), a partir da voz de Michel Temer, vice-presidente do governo Dilma Rousseff em seu segundo mandato, o qual assumiu a Presidência da República interinamente quando do afastamento de Dilma em função do processo de impeachment. Tal como foi desenvolvido em minha tese de doutorado (VINHAS, 2014), compreendo a voz como uma forma de existência material, e, por ser assim entendida, opera discursivamente entre ideologia e inconsciente. A opacidade da voz revela o funcionamento da subjetividade, duplamente afetada em sua contradição constitutiva.

A voz do Presidente Interino será aqui analisada com o objetivo de refletir sobre essa dupla afetação. O corpus a ser investigado é o pronunciamento feito por conta de sua posse como Interino, substituindo a Presidenta afastada, no dia 12 de maio de 2016 . No

${ }^{1}$ Faço alusão às conversas gravadas por Sérgio Machado. 
pronunciamento de quase 30 minutos, nós nos deparamos com algo que não funciona bem... algo que falha. Trata-se da voz de Michel Temer, raramente escutada durante o tempo em que representava o Governo Dilma.

\section{COMO SE CONSTRÓI UM GOLPE DE ESTADO? PRECISAMOS FALAR SOBRE AS CONDIÇÕES DE PRODUÇÃO DO DISCURSO}

A extinção de ministérios, recuos nas investigações da operação lava-jato, a nomeação de homens acusados de corrupção para a composição do alto escalão do governo, corte de investimentos na Educação e na Saúde: essas são algumas das diferenças impostas pelo Interino em poucos dias de governo. Claramente, percebe-se que a proposta de governo de Michel em nada se assemelha à proposta pela qual foi responsável juntamente com Dilma em 2014. É evidente o estranhamento que emerge a partir da imagem de um governo chefiado somente por homens brancos, radicalmente antagônica à composição do governo de Rousseff, fato que caminha na mesma direção da extinção do Ministério da Cultura (mesmo que temporariamente) e do Ministério das Mulheres, da Igualdade Racial e dos Direitos Humanos.

Causa desconforto o fato de que Dilma e Michel concorreram juntos à Presidência da República em 2014. Os dois candidatos constituíram uma chapa para a Presidência: Dilma como Presidenta e Michel como vice-presidente. A chapa, portanto, possuía (imaginariamente) um único projeto de governo, e foi nesse projeto de governo em que mais de 54 milhões de brasileiras e brasileiros votaram em outubro de 2014, reelegendo ambos para a Presidência da República. No entanto, o então Presidente Interino (de 12 de maio a 31 de agosto de 2016) propôs um projeto inquietantemente contraditório àquele da sua candidatura, $\mathrm{o}$ qual se concretizou com a perda do mandato da Presidenta: diminuição da máquina pública, incentivo a parcerias públicoprivadas, instauração de políticas meritocráticas, alianças com setores ideologicamente incompatíveis, redução dos direitos dos trabalhadores, congelamento de investimentos em saúde, educação e assistência social, dentre muitos outros retrocessos à democracia brasileira. Como pode candidatos eleitos pela mesma chapa terem projetos de governo tão diferentes?

As vozes capturadas nos áudios de Sérgio Machado só corroboram a institucionalização do golpe no Congresso Nacional. Michel Temer surge como a única alternativa para uma Presidenta que se nega a renunciar e a pedir uma licença, pois, assumindo como Presidente Interino, poderia tomar as medidas necessárias para agradar à elite empresarial brasileira e à classe política investigada na operação lava-jato. Neste contexto, portanto, as condições de produção do discurso emergem como aquilo que, segundo Courtine (2009), tem íntima relação com o conceito de formação discursiva, sendo parte das contradições ideológicas de classe. Podemos, de forma antecipada, relacionar as práticas políticas ocorridas no Brasil à forma como opera o funcionamento discursivo através das relações de aliança e antagonismo entre as formações discursivas e as contradições que lhes são constitutivas. A voz que não se ouvia de Michel Temer se materializa como algo novo no jogo dos significantes, e as perguntas que podemos fazer são: quem ganhou? Ganhou o quê? Como? Por quê?

\section{COMO DEVE SER UM PRESIDENTE DA REPÚBLICA NO BRASIL? PRECISAMOS FALAR SOBRE A VOZ DE MICHEL TEMER EM SEU PRIMEIRO PRONUNCIAMENTO COMO PRESIDENTE INTERINO}

O primeiro pronunciamento de Michel Temer como Presidente Interino do Brasil ocorreu no mesmo dia do afastamento da Presidenta Dilma. Com um discurso que durou um pouco menos de 30 minutos, Michel trouxe elementos estranhamente contrários às políticas preconizadas pelo governo liderado por Dilma. No entanto, aqui não será o espaço de discussão desses elementos: precisamos falar sobre a voz de Temer, uma voz que quase não é ouvida durante os mais de cinco anos em que foi vicepresidente e que, em momento de grande importância política, enrouquece. Nas redes sociais online, as repercussões sobre a voz de Temer foram implacáveis: internautas apelidaram-no de Nosferatu e de satanista; disseram que sua voz era diabólica e fantasmagórica. Diferentes vídeos surgiram com edições macabras cujas trilhas sonoras foram resgatadas de filmes de terror. Tais elementos evidenciam que a materialidade vocal fez circular diferentes efeitos de sentido, não só através do humor, mas, também, através de duras críticas ao teor sinistro de seu pronunciamento. Em (01), podemos observar o trecho da fala em que acontece essa 
falha no seu primeiro pronunciamento como Presidente. Em itálico estão especificados os momentos em que a voz fica rouca, impedindo-lhe que continue sua fala ${ }^{2}$ conforme o programado.

(01) Recorte da fala de Michel Temer em seu primeiro pronunciamento como Presidente Interino (NBR, 2016).

(SD) E, para isso, é que nós queremos uma base parlamentar sólida, que nos permita conversar com a classe política e, também, com a sociedade [palmas]. Executivo e legislativo precisam trabalhar em harmonia e de forma integrada, até porque, no Congresso Nacional, é que estão representadas todas as correntes de opinião da sociedade brasileira, não é apenas no Executivo. Lá no Congresso Nacional estão todos os votos de todos os brasileiros, portanto [tosse] nós temos que governar em conjunto, água, só física, né o resto vai bem [risadinha, bebe água]. Então [tosse] nós vamos precisar muito da governabilidade e a governabilidade exige além do que eu chamo de Governança, que é o apoio da classe política, do Congresso Nacional, precisa também de governabilidade, que é o apoio do povo, o povo precisa colaborar e aplaudir as medidas que venhamos a tomar. [...] De imediato, precisamos também restaurar o equilíbrio das contas públicas, trazendo a evolução do endividamento do setor público de volta ao patamar de sustentabilidade ao longo do tempo. Quanto mais cedo formos capazes de reequilibrar as contas públicas, mais rápido conseguiremos retomar o crescimento. A primeira medida na linha desta redução está, ainda que modestamente, aqui representada: já eliminamos vários ministérios da máquina pública [aplausos]. E, ao mesmo tempo [tosse], e ao mesmo tempo nós não vamos parar por aí. Já estão [tosse, riso, olhar para a plateia] encomendados [tosse e bebe água] tenho que pedir tenho que pedir uma pastilha [limpa a garganta] já estão encomendados [vozes da plateia] estudos para eliminar [estende a mão para pegar a pastilha] para eliminar [limpa a garganta e pega a pastilha] chega é muito [riso] já estão [rouquidão e come a pastilha] encomendados estudos [palmas] para eliminar cargos comissionados [palmas palmas] e funções gratificadas [palmas e pastilha e pessoas gritando MICHEL MICHEL] sabidamente, funções gratificadas desnecessárias, sabidamente na casa de milhares de funções comissionadas.

O recorte que opero no corpus sob análise é referente ao excerto do texto oral que sofre a intervenção de uma voz rouca, solapada, que não estava prevista no ritual do pronunciamento. Algo além do emprego da mesóclise soa estranho na fala de Michel. O interino limpa a garganta, bebe água, come uma pastilha, tosse, fica sem voz, sorri e olha para a plateia de forma desconcertada. Então, pergunto: como deve ser interpretada a voz de Michel Temer? Seriam simples engasgos, uma rouquidão arbitrária? Uma mera afonia de alguém que, de repente, precisou falar para toda a nação brasileira? Ou, visto de outro modo: poderia ser algo de uma outra ordem (discursiva) irrompendo no intradiscurso?

O que isso significa, então? Poderíamos encerrar esta reflexão neste exato ponto, sem refletir sobre as causas daquilo que falhou; no entanto, pretendo empreender um breve exercício de análise sobre o que transborda na voz de Michel, algo de uma ordem que foge do seu controle de Presidente Interino, e que causa um constrangimento imprevisto em um momento-chave de sua vida política. Sendo assim, precisamos falar sobre a voz de Michel Temer através de um olhar discursivo e, é claro, psicanalítico, visto que estamos tratando, diretamente, da subjetividade na sua dupla afetação inconsciente e ideológica.

O recorte no corpus empírico é operado, neste estudo, a partir do estranhamento materializado na voz de Michel Temer, enquanto "aquilo que parece não caber ser dito num dado discurso" (ERNST, 2009, p. 2). Conforme Ernst (2009), a escolha de um determinado aspecto para ser analisado, em pesquisas cujo embasamento está na Análise de Discurso, "[...] depende da dinâmica do discurso, a ser observada pelo analista, aí implicados o sujeito submetido à ordem da ideologia e do inconsciente, a memória estruturante do dizer e o sentido opacificante" (p. 01). Tais elementos não podem ser desconsiderados pelo analista, desde o momento do recorte do corpus empírico até a descrição e interpretação do corpus discursivo. É importante mencionar que, quando se fala em discurso, não falo da língua, mas de uma materialidade diretamente relacionada à ideologia. O momento político e jurídico vivido por Michel traz à tona, não só através do texto que enuncia, mas, também, de sua voz, a ideologia

${ }^{2} \mathrm{O}$ trecho destacado inicia em 14 min 10 s.

Vinhas | Precisamos falar sobre Temer: o estranhamento navoz 
dissolvida na tentativa de unificação de um país dividido ideológica e politicamente; ou, melhor dizendo, um discurso nacionalista, representado pela bandeira nacional e pelo lema "Ordem e Progresso", travestido de discurso de conciliação.

O estranhamento, portanto, é entendido como o elemento que marca o início da presente trajetória analítica. Diz respeito a algo inesperado que surge intradiscursivamente, relacionado ao interdiscurso. O fato de Temer enunciar, pela primeira vez, do lugar de Presidente, e romper com a fluidez e oratória que se espera de um Presidente, como algo que tropeça na reprodução do ritual, diz respeito ao estranhamento aqui identificado. É por isso que Ernst (2009) fala que o conceito de estranhamento deve ser interpretado numa dupla dimensão: a do intradiscurso, enquanto a materialidade discursiva, e a do interdiscurso, ou seja, a memória discursiva.

Neste momento, então, torna-se necessário trazer à tona o conceito de estranhamento proposto por Ernst (2009, p. 3), a partir do qual desenvolver-se-á a análise:

Estratégia discursiva que expõe o conflito entre formações discursivas e consiste na apresentação de elementos intradiscursivos - palavras, expressões e/ou orações - e interdiscursivos, da ordem do excêntrico, isto é, daquilo que se situa fora do que está sendo dito, mas que incide na cadeia significante, marcando uma desordem no enunciado. Aqui se dá o efeito de pré-construído através do qual "um elemento irrompe no enunciado como se tivesse sido pensado antes, em outro lugar, independentemente", rompendo (ou não) a estrutura linear do enunciado. Possui como características a imprevisibilidade, a inadequação e o distanciamento daquilo que é esperado (grifos da autora).

$\mathrm{Na}$ materialidade, o que chama a atenção concerne à falta de cadência de uma fala referente àquele que deveria ter uma fala perfeita, segundo a representação que se tem de um Presidente da República, mesmo que Interino. Ademais, Michel carrega consigo um apreço pela literatura e pela gramática normativa, o que acaba, talvez, constituindo uma representação de homem público ausente em Dilma e em Lula, por exemplo. Escritor de poemas, teve seus versos publicados em livro; além disso, já se sabe sobre o emprego pouco usual da mesóclise, prática que traz à tona a representação que tem de seu interlocutor. Sua fala atravessada por irregularidades vocais traz um texto caracteristicamente reacionário, especialmente no trecho em que precisa interromper o seu discurso, tomar água e comer uma pastilha, a saber: (SD’) "já estão [tosse, riso, olhar para a plateia] encomendados [tosse e bebe água] tenho que pedir tenho que pedir uma pastilha [limpa a garganta] já estão encomendados [vozes da plateia] estudos para eliminar [estende a mão para pegar a pastilha] para eliminar [limpa a garganta e pega a pastilha] chega é muito [riso] já estão [rouquidão e come a pastilha] encomendados estudos [palmas] para eliminar cargos comissionados [palmas palmas] e funções gratificadas [palmas e pastilha e pessoas gritando MICHEL MICHEL] sabidamente, funções gratificadas desnecessárias na casa de milhares de funções comissionadas".

Vou aqui operar um deslocamento do corpus como gesto analítico, trabalhando no eixo parafrástico e reorganizando-o de modo a eliminar a intromissão da falha vocal. Ficaria assim: (SD") "[...] já estão encomendados estudos para eliminar cargos comissionados e funções gratificadas desnecessárias na casa de milhares de funções comissionadas". É nessa diferença que se embasará a análise que será desenvolvida em breve.

\section{COMO SE DEVE COMPREENDER A VOZ NA ANÁLISE DE DISCURSO? PRECISAMOS FALAR SOBRE A RELAÇÃO ENTRE IDEOLOGIA E INCONSCIENTE NA MATERIALIDADE DISCURSIVA}

Antes de continuar com a análise da voz de Michel Temer pelo ponto de vista discursivo, faço uma pequena pausa para pensarmos teoricamente sobre a voz na Análise de Discurso, e, desse modo, sobre como ocorre a relação entre ideologia e inconsciente a partir desta materialidade específica. Primeiramente, vale salientar um dos pontos basilares da constituição da Análise de Discurso como campo teórico singular nas Ciências Humanas, a saber, a sua formação heterogênea, que abriga fundamentos oriundos do Materialismo Histórico-Dialético, da Linguística e da Psicanálise. Tal ponto se torna importante ao se compreender que a 
concepção de subjetividade trabalhada na AD é trazida da teoria psicanalítica, o que significa dizer que o sujeito é tido como um efeito de unidade produzido por um ego que não tem consciência do desejo que determina a sua estrutura psíquica.

Partindo disso, sujeito e sentido se formam no entremeio entre duas estruturas-funcionamento: a ideologia e o inconsciente. Sujeito e sentido são, desse modo, desde sempre contraditórios. Essa contradição é comumente materializada em elementos (linguísticos ou não) que escapam ao controle do sujeito, por ele produzidos. É o caso do ato falho, por exemplo, que produz um rompimento em uma ilusória coerência/cadência discursiva, a qual é rachada por meio do atravessamento das formações do inconsciente, colocando para o sujeito a evidência de o que ele realmente é.

Esses elementos que escapam ao sujeito podem, no olhar do analista, surgir como o próprio estranhamento sobre o qual falava anteriormente. Os chistes e os lapsos, por exemplo, além dos sintomas e dos sonhos, são formações do inconsciente que colocam, no eixo da formulação, algo de uma outra ordem, aparentemente sem uma relação direta à formação discursiva com a qual o sujeito se identifica, não sendo, portanto, um efeito do interdiscurso, provocando um jogo antagônico subjetivo. Materialidades que não atualizam os saberes da formação discursiva podem irromper no intradiscurso através da voz, da mesma forma que a voz pode materializar a própria identificação do sujeito, servindo à ideologia. Sendo assim, pensando na materialidade vocal, na presente reflexão, opero um desdobramento no conceito de estranhamento de Ernst (2009), o qual passa a ser aqui entendido como aquilo que parece não caber ser materializado num dado discurso.

A Psicanálise, por ser uma experiência de fala, dá margem para que a voz emerja como um elemento significante importante para a compreensão dos processos de subjetivação, os quais falam diretamente da relação entre o sujeito e a ideologia com a qual se identifica. O próprio Pêcheux (2006), quando analisa o enunciado On a gagné, trata da entonação como elemento importante na transposição de um enunciado do campo esportivo para o campo político, e tal fato não pode passar despercebido pelos analistas de discurso.

Conforme já defendido em Vinhas (2014), da voz parece ecoar a possibilidade de emergência de outro tipo de relação com a ideologia e com o inconsciente. Trata-se de uma relação extremamente instável, imprevisível, que pode trazer à tona sentidos que não podem (e não devem) circular a partir de uma sequência léxico-sintaticamente descritível. Os recursos vocais empregados pelo sujeito colocam em evidência o caráter de incompletude de linguagem e do próprio processo de assujeitamento, o qual não ocorre sem falhas. A repetição vertical, interdiscursiva (COURTINE, 1999), possui lacunas, e são justamente essas lacunas que permitem a emergência do imprevisível na ordem discursiva.

Essa relação diferenciada entre ideologia e inconsciente tem embasamento na compreensão de que a voz permite a emergência da singularidade subjetiva. Tal pensamento vai ao encontro do proposto por Souza (2009, p.15), cujo estudo objetiva "[...] tocar a voz como dimensão subjacente ao discurso, contraparte temporal e material da enunciação que possibilita a aparição do sujeito". Se a voz permite a aparição do sujeito, poderíamos dizer que a voz é o intervalo entre significantes? Tal questionamento nos aproxima da noção de lalíngua, mas não me estenderei neste ponto. Precisamos falar sobre a voz de Michel Temer ${ }^{3}$.

Souza (2009) ainda menciona que entende a "voz como acontecimento enunciativo que se singulariza no limiar de uma discursividade" (2009, p. 15). É devido a isso que se admite uma diferença na relação entre a ideologia e o inconsciente, ou seja, ela acontece por singularização. Retomo, assim, as palavras de Piovezani (2009), quando diz que a voz é fragmento de uma subjetividade e da instituição: assujeitamento e resistência convivem na voz como materialidade (da ideologia e do desejo), e abrem mais espaço para a emergência da singularidade.

A singularidade pode ser entendida com base no postulado por Souza (2013, p.179), em estudo acerca da relação entre subjetividade e voz:

${ }^{3}$ Em Vinhas (2014) é feita uma discussão sobre esta relação. 
O procedimento analítico pressuposto aqui conduz a seccionar a superfície discursiva, de modo a individualizar seus elementos materiais constituintes, entre os quais se destacam a linguagem, o inconsciente e a ideologia. Se esses últimos - inconsciente e ideologia -, conforme elucida Eni Orlandi, estão materialmente articulados mediante a linguagem; e se a base material do discurso está na enunciação, conforme postula Pêcheux, arrisco-me a ultrapassar a linha sintática da plataforma enunciativa e depreender nela a voz como gesto que advém antes, na qualidade do singular, e faz o jogo da linguagem no discurso. Aí está: no intervalo entre a língua e o discurso, o drama se interpõe e indica o que, na voz, irrompe como gesto a significar, como sinalização da voz convertida em dêixis do sujeito.

Vejamos, então, o que podemos interpretar a partir da voz de Michel Temer.

\section{COMO COMPREENDER A VOZ DE TEMER DISCURSIVAMENTE? PRECISAMOS FALAR SOBRE ALGO QUE ESCAPA NO PROCESSO DE INTERPELAÇÃO IDEOLÓGICA}

Vamos começar esta seção trabalhando sobre a sequência discursiva recortada a partir de todo o pronunciamento de Michel Temer. Temos, então, a sequência completa exposta em (01), a qual foi recortada em um excerto ainda menor para a presente discussão. Sendo assim, temos a sequência em que o Interino mais tropeça nas falhas de sua voz, conforme pode ser observado em (02):

(02) Sequência recortada a partir da fala de Michel Temer, denominada SD'.

(SD'): já estão [tosse, riso, olhar para a plateia] encomendados [tosse e bebe água] tenho que pedir tenho que pedir uma pastilha [limpa a garganta] já estão encomendados [vozes da plateia] estudos para eliminar [estende a mão para pegar a pastilha] para eliminar [limpa a garganta e pega a pastilha] chega é muito [riso] já estão [rouquidão e come a pastilha] encomendados estudos [palmas] para eliminar cargos comissionados [palmas palmas] e funções gratificadas [palmas e pastilha e pessoas gritando MICHEL MICHEL] sabidamente, funções gratificadas desnecessárias na casa de milhares de funções comissionadas.

Podemos comparar a sequência descrita como SD', recortada literalmente da fala de Temer, à sequência descrita como SD”, na qual operamos uma diferença: na segunda sequência, materializamos a fala de Michel sem as intervenções presentes na linearidade significante, a fim de provocar um questionamento sobre o processo de circulação de sentidos a partir dessas duas falas. Desse modo, a fala de Michel sem os obstáculos vocais ficaria assim:

(03) Paráfrase da sequência recortada da fala de Michel Temer:

(SD”): já estão encomendados estudos para eliminar cargos comissionados e funções gratificadas desnecessárias na casa de milhares de funções comissionadas.

A diferença na materialidade nos faz desconfiar de uma diferença discursiva. Quem nos aponta isso é o próprio Michel Pêcheux que, na abertura do Colóquio Matérialités discursives, afirma: "ce qui, à un moment donné, fait irruption dans l'espace de la

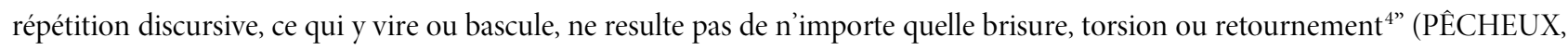
1981, p. 18). Tal citação aponta para a influência do interdiscurso no processo de circulação dos sentidos, totalmente dependente da forma como esses sentidos são materializados. Apesar de ter a aparência de um processo estável e sem falhas, a previsibilidade

4 "O que, em determinado momento, irrompe no espaço da repetição discursiva, o que vira ou se balança, não resulta de qualquer ruptura, torção ou giro" (tradução minha). 
inerente ao processo de atualização dos saberes no intradiscurso pode sofrer rompimentos, torções, rupturas, giros, os quais não somente ganham existência concreta a partir dos jogos léxico-sintáticos próprios da estrutura da língua. Aí é que entra a voz como porta-voz, ou seja, como evidência da mesma ruptura doravante somente sintagmaticamente capturada.

Assim, ao se trabalhar com a voz como evidência do não previsto no ritual, temos que tal processo se dá em função da atuação do inconsciente na subjetivação. É assim que Souza (2009), conforme já mencionado, compreende a voz como acontecimento enunciativo no limiar de uma discursividade: a voz irregular de Michel Temer poderia ser interpretada, então, como a materialização de uma nova posição-sujeito surgindo no complexo organizado de saberes de uma formação discursiva.

Mas não só isso: se fazemos uma leitura mais próxima dos pressupostos psicanalíticos, podemos ter a voz enquanto inscrita como efeito do real da língua, ou seja, como mais próxima da experiência do inconsciente. A voz despontaria da realidade do inconsciente fazendo aparecer o sujeito, aquele compreendido como o intervalo entre significantes, posto que a voz está presente em um momento anterior à linguagem. Em Psicanálise, tem-se que aquilo que é excluído do Simbólico retorna no Real, sendo este o resto, o qual não encontra escape na cadeia significante: é o impossível de ser representado pela língua. Quando há esse retorno ao Real, há uma perturbação na própria voz: na afonia e na gagueira, por exemplo ${ }^{5}$. Desse modo, pela voz podemos chegar mais perto daquilo que é próprio da singularidade subjetiva.

Avançando mais na teoria psicanalítica, podemos falar sobre a angústia e a sua relação com a voz. Segundo Maliska (2006, p. 151),

O termo Angst, na língua alemã, dá ideia de estreitamento, de constrição, é aquilo que engasga, que não sai boca afora; tal como uma rouquidão vocal, uma tosse, um suspiro, um gemido, uma dispneia. Não ao acaso, fenômenos típicos da histeria. A Angst é querer falar quando a voz falha, é aquilo que entala, em que o sujeito fica paralisado, afônico, falta-lhe o ar para respirar, para falar.

Maliska (2006, p. 151) ainda menciona que “[...] a voz disritmada é o efeito daquilo que não se deixa enganar". É nesse sentido que a angústia promove as "falhas" na voz de quem quer dizer algo. O mesmo autor diz que a voz é "manifestação inconsciente que é traduzida no real do corpo, fazendo com que o sujeito titubeie aí onde emerge um sujeito que falta” (p. 152), sendo que no real do corpo são entendidas as manifestações de gagueiras, crises de tosse, afonias. O autor ainda diz que "[...] a voz que falta é o desejo reprimido, aquilo que se furta ao sujeito na execução da voz" (MALISKA, 2006, p. 152).

Sendo assim, através desta breve exposição, compreendemos que as falhas na voz de Temer não podem ser interpretadas alheias ao ritual da interpelação ideológica e do processo de subjetivação, compreendendo que o ritual possui falhas e a subjetivação não é o efeito de um processo de identificação plena. A voz é, então, a representante de um outro lugar, o próprio Real, de onde surgem os efeitos da falta de controle do sujeito sobre o seu desejo. A falta constitutiva da subjetividade é presentificada em ato através das falhas vocalmente materializadas, o que dá concretude à divisão subjetiva (ou contradição subjetiva) em inconsciente e ideologia.

Podemos terminar esta explanação com uma citação de Magalhães e Mariani (2010, p. 404). As autoras dizem que

\footnotetext{
E aqui o entremeio com a Psicanálise e com o Materialismo Histórico se fazem presentes na teoria da Análise do Discurso, posto que o sem-sentido provocado pelo inconsciente e a contradição presente nos rituais de interpelação ideológica sempre fraturam e colocam à mostra o teatro da consciência. Em suma, há um ponto de impossível - marcado na ordem da língua pelo ato falho, pelo chiste e pelas contradições - que torna visível o fato de que não há um assujeitamento total, uma alienação completa do sujeito.
}

A fratura na voz de Michel Temer nos conduz à interpretação de que há, aí, algo que não devia ser mostrado e acabou sendo colocado em evidência no ritual do qual era protagonista. A divisão de Temer, a intromissão de uma outra posição-sujeito através do acontecimento enunciativo denunciado por sua voz, nos permite apontar para a tese de Sloterdijk sobre o funcionamento cínico da ideologia: "Eles sabem muito bem o que estão fazendo, mas mesmo assim o fazem" (apud ZIZEK, 1992, p. 59). Concluo,

\footnotetext{
${ }^{5}$ As teorizações deste parágrafo foram originadas a partir de palestra de Maurício Maliska no 4 o Encontro da Rede Sul Letras, ocorrido em Palhoça, de 11 a 13 de maio de 2016 .
} 
neste trabalho, que o funcionamento cínico da ideologia é denunciado pela posição-sujeito que emerge com a voz solapada - é o próprio inconsciente agindo diretamente no processo de interpelação ideológica.

\section{REFERÊNCIAS}

COURTINE, Jean-Jacques. O chapéu de Clementis. Observações sobre a memória e o esquecimento na enunciação do discurso político. In: INDURSKY, Freda; FERREIRA, Maria Cristina Leandro. (Org.) Os múltiplos territórios da Análise do Discurso. Porto Alegre: Editora Sagra Luzzatto, 1999. p. 15-22.

. Análise do discurso político: o discurso comunista endereçado aos cristãos. Tradução de Cristina de Campos Velho Birck et al. São Carlos: EdUFSCar, 2009.

ERNST, A. G. A falta, o excesso e o estranhamento na constituição/interpretação do corpus discursivo. In: SEMINÁRIO DE ESTUdOS EM ANÁLISE DO DISCURSO, 4., 2009, Porto Alegre, RS. Anais... Porto Alegre: UFRGS, 2009. Disponível em: $<$ http://anaisdosead.com.br/4SEAD/SIMPOSIOS/AracyErnstPereira.pdf>. Acesso em 5 de abril de 2016.

MAGALHÃES, Belmira; MARIANI, Bethânia. Processos de subjetivação e identificação: ideologia e inconsciente. Linguagem em (Dis)curso, Palhoça, SC, v. 10, n. 2, p. 391-408, maio/ago. 2010.

MALISKA, Maurício Eugênio. A voz e a angústia. In: LEITE, Nina Virgínia de Araújo. (Org.) Corpolinguagem. Angústia: o afeto que não engana. Campinas: Mercado de Letras, 2006, p. 149-156.

NBR. Pronunciamento do Presidente Michel Temer (Parte 1) 12/05/2016. Brasília: NBR, 2016. Disponível em: < https://www.youtube.com/watch?v=a8wnalqYz-w>. Acesso em: 20 out. 2017.

PÊCHEUX, Michel. O discurso: estrutura ou acontecimento. 4.ed. Campinas: Pontes, 2006.

Ouverture du colloque. In: CONEIN, Bernard; COURTINE, Jean-Jacques; GADET, Françoise; MARANDIN, JeanMarie; PÊCHEUX, Michel (Org.) Matérialités discursives. Lille: Presses Universitaires de Lille, 1981. p. 15-18.

; FUCHS, Catherine. A propósito da Análise Automática do Discurso: Atualização e perspectivas (1975). In: GADET, Françoise; HAK, Tony. (Org.) Por uma análise automática do discurso: uma introdução à obra de Michel Pêcheux. 3.ed. Campinas: Editora da UNICAMP, 1997.p. 163-252.

PIOVEZANI, Carlos. Verbo, corpo e voz: dispositivos de fala pública e produção de verdade no discurso político. São Paulo: Ed. UNESP, 2009. 
SOUZA, Pedro de. Michel Foucault: o trajeto da voz na ordem do discurso. Campinas: Editora RG, 2009.

O sujeito no discurso: modulações operadas pelo drama na voz. In: PETRI, Verli; DIAS, Cristiane. (Org.) Análise do discurso em perspectiva: teoria, método e análise. Santa Maria: Editoria da UFSM, 2013. p. 175-190.

VINHAS, Luciana Iost. Discurso, corpo e linguagem: Processos de subjetivação no cárcere feminino. 2014. 288 f. Tese (Doutorado em Letras) - Instituto de Letras, Universidade Federal do Rio Grande do Sul, Porto Alegre, 2014.

ZIZEK, Slavoj. Eles não sabem o que fazem: o sublime objeto da ideologia. Trad. Vera Ribeiro. Rio de Janeiro: Jorge Zahar, 1992. 